\title{
Factors of Acceptance for Mobile Learning in Corporate Settings: An Empirical Investigation in Banking Industry
}

\author{
Ayse Kok \\ Management Information Systems Department, Bogazici University, Istanbul, Turkey \\ Email: ayshe.kok@gmail.com
}

Received July 2, 2013; revised August 1, 2013; accepted August 13, 2013

Copyright (C) 2013 Ayse Kok. This is an open access article distributed under the Creative Commons Attribution License, which permits unrestricted use, distribution, and reproduction in any medium, provided the original work is properly cited.

\begin{abstract}
Due to the proliferation of mobile technology and devices like smartphones and tablet PCs into our daily lives, mlearning attracts also more attention in professional training in enterprises. Derived from these statements, this research paper is focused on the following question: what are acceptance factors for m-learning (mobile learning) in the organizational setting? The paper analyzes a real experience in m-learning for training the banking personnel in an international banking institution in Turkey. For this purpose, a mobile virtual learning environment called as mFOR@ was developed and implemented, which was designed to support the training and development process for employees using Pocket PCs. The participants of the training activity (13 professionals) evaluated the m-learning experience via a semi-structured interview; all the content and interactions within mFOR@ were analyzed via content analysis. As a basis for a successful implementation in professional training in enterprises, the acceptance by decision makers and the learners is critical. That is the reason why I present a qualitative analysis of acceptance and the perceived value of m-learning in a corporate setting.
\end{abstract}

Keywords: M-Learning; Mobile Learning; Corporate Training; Acceptance

\section{Introduction}

Nowadays, many possibilities exist in terms of the enhancement and redesign in organizational and training context processes due to the growing development and diffusion of mobile technologies. Among them, mobile technologies enable learning to occur in any setting or at any moment, according to organizational and individual needs.

Mobility now represents a constant in the lives of many workers in the most diverse fields of work (Kristoffersen and Ljungberg, 2000). These technologies contribute to teaching and learning processes not being limited to classroom environments, thus learning can be accomplished in various settings and with flexible hours, allowing mobile professionals to stay where they need to be: whether it be in the field or about handling customers, providing services, doing business or developing projects.

As different needs are emerging, subject to the context where learners are found, it becomes increasingly necessary to be PDA or smartphones and learn on a continuous basis to meet all the demands of a dynamic, competitive and quite unpredictable market.
M-learning actually seems to be a promising emerging market for the training industry. Yet, while process before implementing m-learning as professional training in enterprises, the first step has to be a look at the acceptance at the individual level with a focus on decisionmakers and learners. This gap should be filled a little more in the following qualitative research study.

\section{Literature Review}

Although there are many studies which focus on this important aspect or briefly touching the topic already exist [1] these studies more or less all emphasize quantitative research approaches, either focusing on technology acceptance [2] e.g. using the TAM-Technology Acceptance Model of Davis/Bagozzi/Warshaw (1975), or paradigm changes in general educational contexts, teacher training contexts [3] or higher education contexts [4].

As this literature review shows a lack of information can be found and shown in qualitative research dealing with acceptance, chances, and problems in the field of $\mathrm{m}$-learning for professional training in enterprises. All the existing research focuses on how m-learning works and how it can be defined and analyzed. 


\subsection{Searching and Selection Procedures}

The search for relevant literature was completed in two stages. First, I examined peer reviewed articles that I found in electronic databases using keyword searches including mobile learning, wireless learning, and handheld devices. I used Academic Search Premier, Business Source Premier, Communication and Mass Media Complete, ERIC, Library, Information Science and Technology Abstracts, and PsycARTICLES. In the second stage, I used the "snowball" method by searching for journal articles, as well as articles presented in peer reviewed conferences that are cited in some of the articles that we had read. Altogether, as at 28 January, 2013, 120 articles were analysed and 81 of them were deleted. The 81 articles were discarded because they were opinion papers, conceptual articles or non-empirical descriptions of program implementations.

\subsection{Research Topics and Findings}

Most definitions of mobile learning (m-learning) refer to learning possibilities in different places and/or at different times or, as Gjeddes [5] points out, "m-learning is the acquisition of any knowledge and skill through using mobile technology, anywhere, anytime, that results in an alteration in behaviour". Gjeddes [5] state mobile learning is "any type of learning that takes place in learning environments and spaces that take account of the mobility of technology, mobility of learners and mobility of learning".

A review of the literature suggested that the three most frequent uses of the handhelds centered on utilising the devices as communication, multimedia access, and task management tools. These were followed by the use of handhelds as assessment, capture tools, representational, and analytical tools.

Mobile handheld devices are most commonly used by learners and teachers as communication and multimedia access tools (i.e. accessing multimedia resources such as e-books, databases, web pages, PowerPoint presentations). As these devices were originally designed and created for people to exchange information with one another, considering them as a communication tool makes sense. On the other hand, the dominant use of mobile devices (e.g. PDA or smartphones) as multimedia access tools suggests that the current technology functions primarily as replacement. Waycott et al. [6] asserts that technology as replacement involves technology serving as a different means to the same instructional or learning goal. For example, learners could read an e-book on a PDA or smartphones. This activity replaces the reading of a paper based book with the unchanged learning goal of learner gaining information. An underlying reason for the wide use of PDA or smartphones as replacement technology may be due to the convenience and portability of the handheld devices. Technology as replacement may be contrasted with technology functioning as transformation [6]. The latter has the potential to reorganise learners' cognitive processes and problem solving activities such as using graphing tools for exploratory data analysis, data organisation, and testing hypotheses related to the data [7]. Another plausible reason for the current wide use of PDA or smartphones as replacement technology is that learners and teachers are new to using such devices for learning purposes; hence they are still exploring them. Technology integration stage theorists would view such users as being located in the familiarisation stage [8].

A majority of the studies tend to place greater emphasis on the features of the mobile devices and procedures for using them, rather than on the theoretical rationale or justification for using them. Most of these studies suggest that learners' learning is enhanced through the use of mobile handheld devices. Yet, due to the lack of rigorous research, this statement should be viewed with caution. I will describe this issue in greater detail in the next section "Limitations of previous studies."

The use of theoretical foundations will help inform the pedagogy of using them-a key success factor to the successful use of mobile devices to enhance learning [9]. Some of the theoretical foundations relevant to learning in a m-learning environment might include activity theory [10] and conversation theory Gjeddes [5]. Results suggested that previous studies that examined learners' learning appeared to focus on two types of Gagne's (1985) learning outcomes - verbal information, and intellectual skills. For example, with regard to the former, five of the ten studies dealt with language learning, in particular the learning of English vocabulary [10]. The remaining five studies appeared to deal with an intellectual skills outcome such as discriminating different types of birds [11-16].

One of the theoretical frameworks that might be useful to examine the uptake of mobile devices in teaching and learning is the use of Everett Rogers' diffusion of innovation theory. Rogers [17] described an innovation as “....an idea, practice, or object that is perceived as new by an individual or other unit of innovation" [17]. Although many would argue that mobile devices such as mobile phones and PDA or smartphones are not really innovative objects in the 21 st century era, Rogers asserted that an innovation need not be a brand new thing, in contrast to what its name implies, but rather is perceived as new by the user. I believe that this might also be the case with the use of mobile devices for learning purposes. For many studies, the uptake of mobile devices was mainly limited to the level of knowledge awareness, possibly due to the short duration of time in which the studies 
were conducted. One aspect of the innovation-complexity, which is the degree to which an innovation is perceived as difficult to use, can hinder the uptake of mobile devices in learning settings. However, issue such as difficulties in inputing data using phone keypads, or small screens may perhaps be an irresolvable dilemma because any attempt to increase screen size or allow for a greater ease of data entry (e.g. via a keyboard), may render the devices bulkier and therefore less portable.

Some authors stated that the cost of using mobile handheld devices (e.g. price of the device, cost of mobile service) is a barrier against introducing the devices into teaching and learning [18,19]. Basole [20] argued that although the cost of a mobile device (e.g., a PDA or smartphones) varies according to functionality, size of memory, and accessory features, it is usually less expensive than desktop and laptop computers. Companies would be interested to know if the money used to introduce devices (e.g. PDA or smartphones, mobile phones) could affect certain outcomes, for example whether learner enrollment is positively affected by use of these devices in completely online courses.

\subsection{Limitations in Previous Empirical Studies}

I found out that four methodological limitations exist concerning previous research studies.

- The experimental method which utilised a one group pretest and posttest design to examine learner learning outcomes due to use of mobile handheld devices use has been widely used, yet this makes the design less weak. According to Ogato \& Yano [16], without a control group, differences found between pretest and posttest scores might not necessarily be attributable to the use of mobile handheld devices such as a PDA or smartphones or mobile phone. By integrating a control group and random assignment of participants into the research design the study could be strengthened considerably [21,22]. Yet, comparing learning outcomes between different media due to the presence of many potential confounding variables makes the task of pinpointing a specific factor or factors that may account for the learning difference difficult, if not impossible [23]. Instead, since different media possess different attributes [24,25], future research studies might focus on investigating where and how to best use mobile devices as an instructional medium.

- A great majority of the previous studies did not report effect sizes in the results or discussion section (the exception being Tan et al.'s 2007 study). The APA Task Force stressed that researchers should provide some effect size estimate such as Cohen's d when reporting a $\mathrm{p}$ value since reporting and interpreting effect sizes is essential to good research [26]. Ogato \&
Yano [16] argued that reporting effect size allows a researcher to judge the magnitude of the differences present between groups, thus increasing the capability of the researcher to judge the practical significance of the results derived.

- Almost half (46\%) of the descriptive research studies based their findings primarily on participants' selfreported data, such as interviews and questionnaire surveys. A general problem of studies based on selfreported data is that participants usually have correct notions about socially desirable answers, which can be referred to as the tendency to provide answers that cause the respondent to look good [27]. Social desirability responding has long been viewed as a potential source of error variance in self-report measures [28, 29].

- A majority of the studies (56\%) were limited in their duration, ranging from as short as a few hours to one semester. Short-term studies cannot fully address some issues that may be critical in helping us understand how the use of mobile handheld devices might evolve over time. Short-term studies may suffer from a novelty effect, where it is possible that learners and teachers are more likely to use the devices because the devices are new to them compared to participants who have used them for a longer period of time. This may introduce a significant bias with respect to the obtained results.

\section{Aim and Research Design of Study}

Given the scarcity of qualitative studies in enterprise settings, the purpose of this qualitative research study is to reflect on and understand the position of mobile learning in professional training in enterprises. Main objective of my research is to clarify which issues are addressed when decision makers responsible for professional training and human resources management in a banking institute in Turkey are reflecting on the acceptance of mobile learning [30] concerning their educational measures in initial and further education at enterprises.

A mobile virtual learning environment called as mFOR@ was developed and implemented within the bank, which was designed to support the training and development for workers using Pocket PCs. The participants of the training activity (13 professionals) evaluated the m-learning experience via a semi-structured interview; all the content and interactions within mFOR@ were analyzed via content analysis. Data has been collected by means of semi-structured interviews based on an interview guideline with responsible decision makers in enterprise. The narrative parts of the interviews are suited to delineate personal meanings [31-33] and experiences. 
My interviews has been documented via audio-recordings, then transcribed and structured via argumentation tables. Content analysis has been used to analyze and categorize the data. To establish trustworthiness the interviews are randomly assigned and analyzed by the authors. Concerning validity it can be stated that all categories that emerged from the data are consistent with the understandings of the participants. The average duration of each interview is about 15 minutes after a first informative telephone contact of about 5 minutes. All interviews have been conducted during February, 2013.

\subsection{General Overview of the Bank and Its Learning Management System}

The Turkish Bank with approximately 9200 employees has the following characteristics with regard to its learning strategy and organization of the Training function.

The company's learning strategy has evolved in the past 6 years. Until 2006, it was more traditionally focused on priorities established by Training \& Decelopment Department under HR Group on the basis of a reactive approach to the requests of managers in the company.

The main delivery system was the classroom and the LMS. Training and learning priorities are established by business leaders as a part of their business plans, and managers are highly involved in the training process.

Training deliverables have shifted from a catalog of courses that focused on content design to a blended mix of learning experiences focused on personalized learning environments making use of new learning Technologies such as social and mobile learning technologies.

The Bank has recently implemented a mobile learning environment with the following characteristics.

\subsubsection{Content Module}

Figure 1 shows the framework design of mobile learning management system; it consists of three modules with two interfaces. They are content module, learning module and evaluation module. Figure 2, shows that the content module consists of five authoring tools i.e. development, management, distribution, collaboration and delivery:

Development tool: Here, content may be developed based on the Dale's cone of experience (Chen et al., 2008), it contains the words or text, images, audio, video, graphics and animations, demonstration of the topic. It mentions the passive learning and also it contains a variety of questions like multiple choice, true or false, short answers and descriptive answers types. It is called as active learning. In this cone of experience of learning process, it improves the learner's passive learning approach to active learning. The major content types are

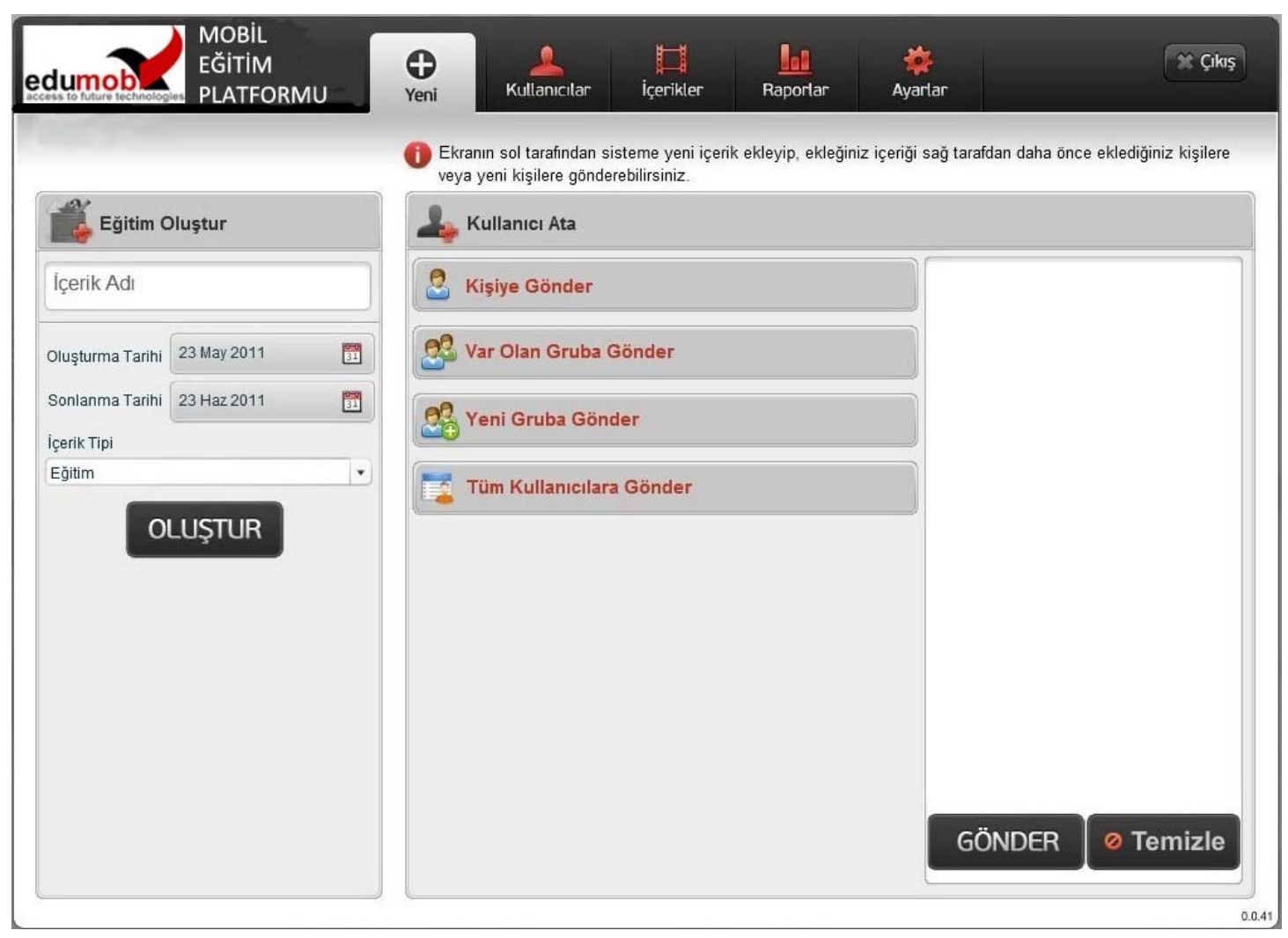

Figure 1. mFOR@ main modules (display in Turkish). 


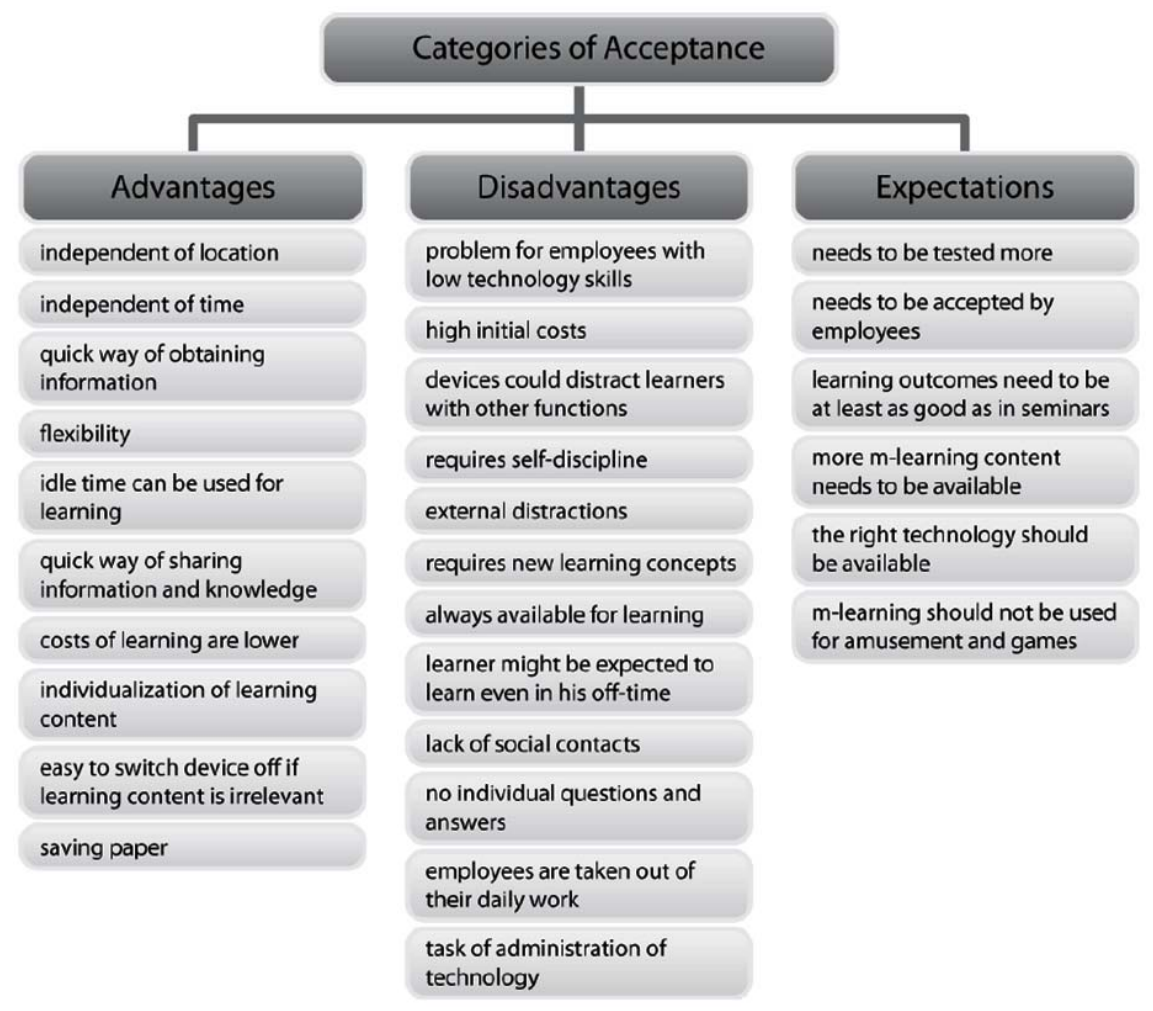

Figure 2. How decision makers in enterprises see the acceptance of the use of $\mathbf{m}$-learning.

web pages in HTML, images in JPEG, Text in PDF or word format, Audio in MP3 or WAV, Video in AVI and MPEG4, animations in Flash for the teachers, there is no need to dictate the notes in the classroom to the learners. Instant available materials can be used in online or offline campus. The teacher or subject experts can develop the m-content with video-based lessons which includes text-based and audio-based lessons. The learners can get the more ability to execute new problems, new ideas and strengthen their knowledge.

Management tool: This contains the storing, retrieving and browsing the required content and the content can also be imported or exported.

Distribution tool: Using this tool, m-content can be distributed through the database servers and web servers, the database server contains the login address and password, they instantly get the details about their personal information, class schedules, time table. From the web server the learner's can download the syllabus, assignments and video-based lessons.

Collaboration tool: This is used to share the knowledge with other learners and teachers with the collected information and experience. The delivery tool can act as m-content which can access via the wireless networks such as wifi, Bluetooth using mobile phones through internet enabled equipments (web-based learning) like PDA or smartphones, notebook computers, palm tops, tablet PCs etc. The use of mobile devices is to delivery performance support and to teach through communication, which are the two important primary delivery strategies.

\subsubsection{Learning Module}

Teacher can conduct the assessment test, online test through this learning module. The learners can access the syllabus, schedules, assignments through wireless networks using mobile phones or wireless devices like PDA or smartphones, note book computers etc. This type of learning can be individualized or personalized selflearning which enhances the problem solving skills and improve their knowledge. It can be easy accessible, privacy, immediacy, permanency. Wireless technology learning system is a state-of-the-art in the field of m-learning due to the benefits of privacy, immediacy, flexibility, accessibility, reliability, security, mobility, reusability, interactivity provided by the video-based content. The learners or teachers have the ability to learn contents from the multiple sources on different devices notebook computer, etc. The learners and teachers can have a close relationship by solving the problems and completing the assignments together. The mobile learning management system can increase the thinking skills, performance and knowledge sharing to learners.

\subsubsection{Evaluation Module}

Wireless mobile learning is two types, m-learning as a 
form of performance support and m-learning as communication that creates knowledge. The m-learning as communication takes a different approach is based on constructivist theories of learning and stem from learners and experts constructing knowledge in an authentic context. Wireless m-learning performance support systems are similar to traditional support. The m-learning solutions integrate mobile devices with the work to help the user perform a task by providing information, guidance and learning experiences when and where needed.

\section{Results}

The interviews focus on ten questions about learning with mobile devices in general and in the enterprise of the interviewees. The decision makers chosen to be interviewed are given the chance of talking about experiences, opinions, plans, and strategy concerning m-learning. The ten guiding questions the interviews are based on are presented below:

- Have you been confronted with m-learning in any way in your company?

- In general, what is the relevance of learning with mobile devices?

- What is the relevance of learning with mobile devices in your company?

- In general, which role will learning with mobile devices play in the near future (next 5 years)?

- Which role will learning with mobile devices play in your company in the near future (next 5 years)?

- Would you say that using mobile learning in companies makes sense or not?

- Which advantages do you see in learning with mobile devices?

- Which disadvantages do you see in learning with mobile devices?

- Would mobile learning fit into your current training program?

- Please describe an example of how the integration of learning with mobile devices into your company could make sense.

Most managers state that mobile devices (mainly smartphones) have already become part of their daily work and are used extensively in many areas such as presenting products or information to clients. So, why haven't mobile devices found their way into the training programs of this company yet?

\subsection{Acceptance of M-Learning in Enterprises}

In order to get a more complete picture of how these companies feel about m-learning I group the statements into categories that have a critical influence on the acceptance level of mobile learning. These categories are the advantages, disadvantages, and expectations associ- ated with the use of mobile devices for learning. An overview of the items in each category is given below. The items are loosely sorted by how frequently they were mentioned with higher frequencies at the top (see Figure 2).

A closer look at the advantages and disadvantages listed reveals that many decision makers might be thinking of m-learning as simply moving their current learning methods like seminars and handbooks to mobile devices. This is very evident in the following statements:

"Easy to switch device off if learning content is irrelevant";

"No individual questions and answers".

Very few of the decision makers mentioned the opportunity for the "individualization of learning content" in terms of the advantages. This could be either because they aren't aware of solutions that exist or because the solutions they need in their enterprise aren't available yet. In any case, this is a clear challenge for m-learning providers to become active and either develop the right $\mathrm{m}$ learning methods and content or to keep decision makers better informed about their products.

Moreover, the following statements show that there is also uncertainty if the new approaches work or can provide positive learning results:

"Needs to be tested more";

"Learning outcomes need to be at least as good as in seminars".

The following statement even shows that new approaches which come with m-learning like serious games could actually be a good alternative way of learning.

"M-learning should not be used for amusement and games".

Based on these statements, it should be mentioned that it is important to evaluate m-learning approaches and methods scientifically and find out how effective these approaches are, at least until enterprises have had enough time for practical experiences. This would be the challenge for the scientific community.

The uncertainty of decision makers also highlights the need for showcases and best practice cases. The situation indicates that m-learning in this enterprise is still in its infancy, and it will take an effort on several levels in order to turn it into an important part of further professional training.

\subsection{Chances for Enterprises that Make Use of M-Learning}

The aspects of "chances" that mobile learning provides for this company as seen by the decision makers can summarized in the order of their frequency, grouped by category, as follows:

- Usability and Aims: Respondents list chances in the category usability and aims. This category can be 
characterized as chances concerning main future company goals and aspects which create additional usefulness future. The main statements outlining these chances are:

- Making use of company's online resources

- Attracting new generations

- Saving money

- Organization: The decision makers focus on chances which can be summarized under the category of organization. The chances they see under this category have in common that these are all aspects that improve the processes and organizational structure of measures, courses in the field of initial and/or further training in learning environment. The main statements outlining these chances are:

- Good way of putting information (handbooks, presentations) in the hands of employees

- Use of smartphones as a quick way of distributing information

- Essential for keeping mobile employees connected

- Good for preparing learners for seminars and for providing material after seminars

- Making information available that's up to date

- Possibility of replacing the mandatory seminars

- Employees can take device home and have learning content available

- Learning: Last but not least, the respondents emphasize chances which can be grouped into the category learning. The indicated chances in this category refer to learning contents and learning aims as well as an improvement of the learning process of the users of mobile learning.

- Good for learning about company's products

- Individualized content for learners

- Good for learning languages

- Opportunity for users to provide feedback

- Use of simulations to make understanding easier

Once again it becomes clear from the following statements that the dominant way of understanding m-learning in enterprises is the transfer of established training methods to mobile devices:

"Good way of putting information (handbooks, presentations) in the hands of employees".

However, ideas of new approaches are starting to appear as well although decision makers admit to not knowing very much about these approaches:

"Individualized content for learners";

"Let's users provide feedback";

"Using simulations to make understanding easier".

One of the very interesting chances seen by decision makers is the opportunity to make the company's training programs more attractive to young generations that are more used to mobile devices. This is seen as a good way of attracting high potential employees to the com- pany.

\subsection{Problems for Enterprises that Make Use of M-Learning}

In terms of the real problems for the introduction of m-learning in their company decision makers differentiate between purpose-related problems, cost-related problems, and problems concerning the acceptance and ability in enterprises to deal with matters of m-learning. Their biggest worries are summarized, grouped by category, in the order of their frequency below:

Cost efficiency

- High costs for the technology

- High costs for the content Purpose adequacy

- Uncertainty if results will be good enough to replace current learning methods or if it can just be an addition

- No content available for company's purposes

- No technology available for company's purposes Ability and acceptance

- M-learning will be tested but it is a question of acceptance by the employees

- Willingness to introduce m-learning but company doesn't have the knowledge

The problems mentioned are definitely not insurmountable obstacles but they are currently keeping the interviewed companies from embracing m-learning immediately. Solving these problems would require a good cooperation between company staff and the providers of m-learning solutions, especially when it comes to developing employee-friendly solutions, creating products with convincing learning results, and designing cost-efficient solutions.

\section{Conclusions}

It is essential to study how new technologies like mlearning can contribute to improving the quality of education (cf. Laurel, 1995). Ideally, the scope of this study should include the views of both teachers and participants as teaching and learning processes both involve teachers and learners. This would add to the impressions provided by the decision makers by using the results and categories of this study as a starting point for future interviews and surveys. In addition, it would be useful to find out how current and future generations of employees want to learn, how easy it is for them to accept m-learning, and what their expectations of further education provided by their employer are. Furthermore, it would make sense to repeat the interviews every year and examine how the acceptance and the use of mobile devices for learning purposes in enterprises change since the development of mobile devices proceeds at a very high pace 
and the role of mobile devices in people's daily life increases rapidly. The result of the study is only meaningful for a short time.

This study shows that m-learning is still in its infancy due to the fact that the chances that are seen in m-learning in enterprises are still very simple implementations, with independence of location and time or the quick distribution of information as the main ideas. The ideas remain on a relatively simple level of taking advantage of the m-learning potential, such as providing a way of finding information quickly or the use of podcasts. Individualization of learning content and the chance of reaching new generations through m-learning also play a big role in the companies' willingness to give m-learning a try in the near future.

In order for m-learning to find its way into enterprises, it will be necessary to educate decision makers on how m-learning could work for them. At the same time, there seems to be a lack of good solutions on the market and providers of mobile learning solutions are called on to offer more educational products that can be used for $\mathrm{m}$ learning.

Acceptance of m-learning as a future way of further educating the workforce is surprisingly high. Apparently decision makers are open to innovation in this area if they see that m-learning solutions can fulfill three critical requirements:

\section{Acceptance by the learners}

Depending on the industry, the workforce is expected to accept the use of mobile devices or electronic devices for learning more or less. With younger generations, decision makers expect the acceptance to go up quickly and even predict that mobile learning will be a lot more attractive than holding seminars.

\section{Good learning results}

If an enterprise relies on m-learning, the learning results should be at least as good as the results of current methods like seminars. This of course demands scientific studies of effectiveness and showcases to convince decision makers.

\section{Acceptable costs}

The costs involved should not be higher than the current costs of educating the workforce. Many decision makers are under the impression that m-learning would be expensive because of the high costs of the technology involved. Saving potentials are rarely seen. In order for $\mathrm{m}$-learning to be accepted in enterprises, cost advantages will have to become more apparent.

Based on this research study, the following practical solutions can be suggested for overcoming the barriers of adoption:

- The creation of showcases in which different partners work together on implementing a m-learning approach in a company, study the results, and publish them.
This would require a company willing to try new learning approaches, an academic partner to study the results, a provider of m-learning solutions, and, ideally, a dissemination partner like an association or a government organisation.

- Informing decision makers: The showcase would provide interesting facts to prove that m-learning is a viable alternative, and this would have to be supplemented with information on how other companies could get started with their own m-learning projects.

It is important to remember that the study only shows the current situation of one banking institution in Turkey. Further studies would be needed to expand the result to a European view or even a more global view. As enterprises are in different situations and at different stages of introducing m-learning into their professional training and their on-the-job training, similar studies in other countries would allow an interesting comparison.

\section{REFERENCES}

[1] V. Venkatesh, M. Morris, G. Davis and F. Davis, "User Acceptance of İnformation Technology: Toward a Unified View," MIS Quartely, Vol. 27, No. 3, 2003, pp. 425478.

[2] G. Walsham, "Interpreting Information Systems in Organisations," John Wiley \& Sons, Chichester, 1993.

[3] J. Waycott and A. Hulme, "Learner's Experiences with PDAs for Reading Course Materials," Personal and Ubiquitous Computing, Vol. 7, No. 1, 2003, pp. 30-43. doi:10.1007/s00779-002-0211-x

[4] A. Weilenmann, "Doing Mobility," Tese de Doutorado, Department of Informatics, Göteborg University, Göteborg, 2003.

[5] E. Wenger, "Communities of Practice-Learning, Meaning and İdentity," Cambridge University Press, Cambridge, 1998. doi:10.1017/CBO9780511803932

[6] C. Argyris, "On Organizational Learning," Blackwell, Cambridge, 1992.

[7] R. Basole, "Enterprise Mobility: Researching a New Paradigm," Information Knowledge Systems Management, Vol. 7, No. 1-2, 2008, pp. 1-7.

[8] G. Boterf, "Compétence et Navigation Professionelle," Éditions d'Organisation, Paris, 2000.

[9] J. Brown and D. Metcalf, "Mobile Learning Uptade," 2008. http://www.masie.com

[10] R. Lindgren, O. Henfridsson and U. Schultze, "Desing Priciples for Competence Management Systems: A Synthesis of an Action Research Study," MIS Quartely, Vol. 28, No. 3, 2004, pp. 425-472.

[11] K. Lyytinen and Y. Yoo, "The Next Wave of Nomadic Computing," Information Systems Research, Vol. 13, No. 4, 2002, pp. 377-388. doi:10.1287/isre.13.4.377.75

[12] J. Mills, K. Platts and M. Bourne, "Competence and Resource Architectures," International Journal of Opera- 
tions \& Production Management, Vol. 23, No. 9, 2003, pp. 977-994

[13] H. Collis and R. Hussey, "Pesquisa em Administração," Bookman, Porto Alegre, 2005.

[14] L. Gjedde, "Learning on the Road-Designing for Contextual and Engaging Mobile Learning," Proceedings of IADIS International Conference on Mobile Learning, Algarve, 11-13 April 2008, pp.

[15] C. Hardless, J. Lundin and U. Nulden, "Mobile Competence Development for Nomads," Proceedings of the Hawaii International Conference on Systems Science, Big Island, Hawaii, 3-6 January 2001, pp. doi:10.1109/HICSS.2001.926229

[16] H. Ogata and Y. Yano, "How Ubiquitous Computing can Support Language Learning," 2003. http://www-yano.is.tokushima-u.ac.jp/ogata/clue/ogata-ke st2003.pdf

[17] A. Jeyaraj, J. Rottman and M. Lacity, "A Review of the Predictors, Linkages, and Biases in IT Innovation Adoption Research," Journal of Information Technology, Vol. 21, No. 1, 2006, pp. 1-23. doi:10.1057/palgrave.jit.2000056

[18] A. Jones, K. Issroff and E. Scanlon, "Affective factors in learning with mobile devices," In: M. Sharples, Ed., Big Issues in Mobile Learning, Kaleidoscope, Nottingham, 2007, pp. 17-22.

https://www.zotero.org/lmlg/items/itemKey/4XGZRSCM

[19] N. S. Chen, C. W. Kinshuk and S. J. H. Yang, "Designing a Self-Contained Group Area Network for Ubiquitous Learning," Educational Technology \& Society, Vol. 11, No. 2, 2008, pp. 16-26.

[20] P. Perrenoud, "Construire des Compétences dès l'École," ESF, Paris, 1997.

[21] J. Piaget, "Sociological Studies," Routledge, London, 1995.

[22] M. Kakihara and C. Sorensen, "Mobility: An Extended Perspective," Proceedings of the Hawaii International Conference on System Sciences, Big Island, Hawaii, 7-10 January 2002. doi:10.1109/HICSS.2002.994088

[23] A. Lasen, "Affective Technologies-Emotions and Mobile Phones," 2004. http://www.receiver.vodafone.com/11/articles/pdf/11 03. pdf

[24] J. Sherry and T. Salvador, "Running and Grimacing: The Struggle for Balance in Mobile Work," In: B. Brown, N. Green and R. Harper, Eds., Wireless World-Social and Interactional Aspects of Mobile Age, Springer-Verlag, London, 2002, pp. 108-120.

[25] O. Smørdal and J. Gregory, "Personal Digital Assistants in Medical Education and Practice," Journal of Computer Assisted Learning, Vol. 19, No. 3, 2003, pp. 320-329. doi:10.1046/j.0266-4909.2003.jca_033.x

[26] C. K. Prahalad and G. Hamel, "The Core Competence of the Corporation," Harvard Business Review, 1990, pp. 79-91.

[27] E. M. Rogers, "Diffusion of Innovations," 5th Edition, Free Press, New York, 2003.

[28] M. Sharples, I. S. Arnedillo, M. Milrad and G. Vavoula, "Mobile Learning: Small Devices, Big İssues," 2007. http://telearn.noe-kaleidoscope.org/warehouse/KAL_Lega cy_Mobile_Learning_(001143v1).pdf

[29] C. Sorensen and D. Gibson, "Ubiquitous Visions and Opaque Realities: Professionals Talking about Mobile Technologies," Info: The Journal of Policy, Regulation and Strategy for Telecommunications, Information and Media, Vol. 6, No. 3, 2004, pp. 188-196.

[30] C. Sorensen, A. Al-Taitoon and J. Kietzmann, et al., "Exploring Enterprise Mobility: Lessons from the Field," Information Knowledge Systems Management, Vol. 7, No. 1-2, 2008, pp. 243-271.

[31] A. Trifonova, "Mobile Learning-Review of the Literature," Technical Report DIT-03-009, University of Trento. 2003. http://eprints.unitn.it/archive/00000359/

[32] A. Saccol, "A Teoria da Hospitalidade e o Processo de Adoção de Tecnologias Móveis e Sem Fio," Tese de Doutorado, Faculdade de Economia e Administração, Universidade de São Paulo, São Paulo, 2005.

[33] M. Sharples, "The Design of Personal Mobile Technologies for Lifelong Learning," Computers \& Education, Vol. 34, No. 3-4, 2000, pp. 177-193. doi:10.1016/S0360-1315(99)00044-5 